УДК 339.97

\title{
ДИНАМИКА КОНКУРЕНТОСПОСОБНОСТИ ЭКОНОМИК СТРАН ЕВРАЗИЙСКОГО ЭКОНОМИЧЕСКОГО СОЮЗА*
}

\author{
А.Ш. МАРГАРЯН \\ к.э.н., доцент, декан факультета регулирования экономики и международных экономических отношений, \\ Армянский государственный экономический университет, г.Ереван
}

\section{Д.Р. ГАЛОЯН}

д-р экон наук, доцент кафедры международных экономических отношений Армянский государственный экономическийсуниверситет, г.Ереван

\begin{abstract}
Аннотация
В данной статье была произведена оценка конкурентоспособности стран-членов ЕАСТ на основе данных разных рейтинговых организаций. Структура торговли стран-членов Евразийского экономического союза (ЕАСТ) имеет сырьевое направление и примерно соответствует структуре региональных интеграционных группировок развивающихся стран. Такая структура торговли уменьшает взаимодопольняемость экономик государств-членов EACT, снижает экономический интерес друг к другу, и часто даже делает их соперниками на одниаковых товарных рынках. Структурные проблемы торговли стран-членов являются результатом их техническо-экономического низкого уровня, что приводит к снижению конкурентоспособности этих стран на мировом рынке.
\end{abstract}

Abstract

This article has assessed the competitiveness of EAEU member countries on the basis of different rating organizations. The structure of the trade of the Eurasian Economic Union (EAEU) has raw material direction and roughly corresponds to the structure of regional integration groupings of developing countries. This kind of structure reduces the trade complementarity of the economies of the member states of EAEU, reduces economic interests in each other, and often makes them competitors on the similar commodity markets. Structural problem of trade of member states are the result of their technical and economic low level, which leads to a decrease in their competitiveness in the global market.

\section{ВВЕДЕНИЕ}

Теоретическая проблема конкурентоспособности стран - одна из наиболее актуальных задач в мировой экономике, ибо на ее исследование влияют многие факторы, прежде всего темпы экономического роста стран, уровень безработицы, место страны или национальных отраслей в мировой экономике и т.П. Проблемы конкурентоспособности рассматривались разными учеными в рамках различных теоретических и методологических подходов. Наиболее подходящими для объяснения сущности глобальных факторов конкурентоспособности стран можно считать теории международной торговли и инвестиций М. Портера [1] и А. Смита [2], а также теории Ч. Киндлебергера [3] и Дж. Тобина [4], объясняющие движение капитала различиями в условиях предпринимательской деятельности в разных странах и не увязывающие напрямую движение инвестиций с движением товаров.

Идея регионального сотрудничества развивающихся стран возникла на основе успеха Западноевропейской экономической интеграции. Однако, если интеграция в Западной Европе - это взаимодополняющее сотрудничество конкурентоспособных стран с высокими темпами экономического роста, то для развивающихся стран региональная интеграция - это способ преодоления низкого уровня развития производительных сил, который приведет к повышению конкурентоспособности и укреплению их позиций на мировом рынке. Интеграцию развивающихся стран нельзя считать процессом постоянного углубления экономических, законодательных, финансовых и социальных связей между странами. На современном этапе экономическое сотрудничество развивающихся стран можно рассмотреть, как подготовительную степень интеграционных процессов. Движущей силой экономического сотрудничества являются использование конкретное совокупных преимуществ национального экономического потенциала, интернационализация экономической жизни и интенсификация экономических связей, а конечной целью - модернизация отсталых экономик в условиях формирования масштабного экономического пространства.

Чисто формально интеграционные объединения развивающихся стран можно разделить на следующие формы: таможенный союз, общий рынок, объединения свободной торговли, освоение природных ресурсов, региональные и субрегиональные, валютные и финансовые союзы. По сути, интеграционные процессы в развивающихся странах делятся на несколько типов [5]:

1.Максимальная либерализация внутрирегиональных связей в условиях общей таможенной защиты.

2.В принципе та же форма сотрудничества, что и первая, но с усиленными программами производственной кооперации и отраслевой специализации, которая рассчитана на внутренний рынок.

\footnotetext{
* Исследование выполнено при поддержке ГКН МОН РА в рамках армяно-белорусского совместного научного проекта № 13РБ059 (финансовая поддержка Государственного Комитета Науки при Министерстве образования и науки Республики Армения).
} 
3.Старание развивающихся стран превратить в экономический союз ранее созданные политические объединения.

Интеграция развивающихся стран - это скорее координация экономической политики стран-членов, нежели объективный процесс экономической взаимозависимости и взаимодополнения [6]. На начальном этапе интеграции, внутренняя либерализация региональной торговли и создание большого экономического пространства, которое защищено от иностранной конкуренции общей таможенной преградой, изначально стимулирует развитие импортозамещающих отраслей и увеличивает количество промышленных предприятий.

Этим путем удовлетворяются исключительно потребности внутреннего рынка, благодаря чему внутрирегиональное товарообращение увеличивается. Что касается экономических объединений, то большинство из них прошли тот этап, на котором доля взаимного товарооборота была выше, чем объем собственного товарообращения. Однако, так как в этом случае все преимущества интеграции приходятся на долю наиболее развитых государств, это порождает сопротивление со стороны менее развитого партнера [7]. Именно последние страдают от неравномерного распределения доходов в интеграционных процессах, что в конечном счете приводит к развалу союза или застою экономических отношений. В итоге любые попытки равномерного распределения доходов, выравнивания уровней экономического развития стан обречены на провал. В этом контексте интересно проанализировать конкурентоспособность стран-членов Евразийского экономического союза (ЕАЭС).

\section{РЕЗУЛЬТАТЫ И ИХ ОБСЖДЕНИЕ}

Структура торговли между странами-членами Евразийского экономического союза имеет сырьевое направление и примерно соответствует структуре товарооборота региональных интеграционных группировок развивающихся стран. Такая структура товарооборота уменьшает уровень взаимодополняемости экономик стран-членов, также снижает экономическую заинтересованность друг в друге, а часто даже превращает их в конкурентов в борьбе за те же товарные рынки [8]. Структурные проблемы товарооборота стран Союза являются результатом их низкого уровня технико-экономического развития, что приводит к снижению уровня конкурентоспособности этих стран на мировом рынке. Об этом свидетельствуют данные отчета мировой конкурентоспособности, по которым страны ЕАЭС в 20142015 гг. занимают в среднем 63-е место по индексу глобальной конкурентоспособности (по сравнению с предыдущим годом улучшили свои позиции на один пункт), что выше, чем средний мировой показатель - 72 (в рейтинге оценены показатели 144 стран) (таблица 1).

Лучшую позицию с точки зрения конкурентоспособности среди стран ЕАЭС занимает Казахстан (51-е место в мире), затем Россия - 53-е место, а Армения занимает 85-ое место. Белоруссия в этом рейтинге не участвует. При этом если конкурентоспособность экономик Казахстана и России превосходит средний мировой показатель соответственно на 21 и 19 пунктов, то Армения отстает от среднего мирового показателя на 13 пунктов.

Анализ столбиков конкурентоспособности показывает, что страны ЕАЭС имеют относительно высокую эффективность трудового рынка, довольно развито высшее образование и профессиональный опыт, а также наблюдается макроэкономическая устойчивость и развитые инфраструктур. По этим показателям две страны ЕАЭС - Россия и Казахстан опережают средний мировой показатель, а Армения отстает от последних в среднем на 10 пунктов. Хотя по уровню развития институтов, эффективностью товарного рынка и особенно уровнем развития финансовых рынков эти страны отстают от среднего мирового показателя. С одной стороны, страны ЕАЭС занимают довольно выгодные положения по отдельным индексам (Россия и Казахстан занимают соответственно 7 и 52 места по величине рынка), а с другой стороны, некоторые показатели - инновационный потенциал, здравоохранение и начальное образование, в смысле глобальной конкурентоспособности низкие.

Между исследуемыми тремя странами наблюдается высокая степень диверсификации показателей размеров рынка и макроэкономической стабильности. Однако, если в первом случае естественно, что Россия, будучи самой большой страной мира, имеет высокую степень конкурентоспособности, то различия рейтинга макроэкономической стабильности обусловлены особенностями социально-экономического развития и демографии. Кстати по этому показателю Армения отстает от Казахстана и России соответственно на 50 и 46 пунктов.

По сравнению с 2013-2014гг. показатели конкурентоспособности стран ЕАЭС улучшились только на 1 пункт [10], но если учитывать тот факт, что, по сравнению с прошлым годом, число стран, входяших в рейтинг, снизилось на 4, то можно сказать, что в исследуемый период показатель конкурентоспособности стран не улучшился. По сравнению с прошлым годом, свои показатели заметно улучшила Россия (+11), Казахстан - только на 1 пункт, а показатели Армении ухудшились на целых 6 пунктов. В России в течение года значительно выросла эффективность трудового рынка (+27), товарного рынка (+27), конкурентоспособность институтов (+24), конкурентоспособность компаний $(+21)$.

Спад конкурентоспособности РА в основном обусловлен низким уровнем развития инфраструктур, неэффективной деятельностью институтов, спадом макроэкономической стабильности, снижением эффективности трудового рынка и низким уровнем развития финансового рынка. Повышению конкурентоспособности может способствовать осуществление реформ, направленных на обеспечение максимально высокого экономического роста, потому что в 2013 г. РА значительно отставала от всех стран ЕАЭС по показателям ВВП на душу населения. Но главное, чтобы страна сама стремилась к собственному развитию, не надеясь только на интеграцию. Интеграция - это не альтернативный вариант экономического развития, и она эффективна только в том случайе, если страны конкурентоспособны и находятся в состоянии роста [11]. 
Таблица 1. Индекс конкурентоспособности стран ЕАЭС в 2014-2015 гг. [9]

\begin{tabular}{|c|c|c|c|c|c|c|c|c|c|c|c|c|c|}
\hline \multirow[b]{2}{*}{ Страна } & \multicolumn{12}{|c|}{ Показатели конкурентоспособности } & \multirow[b]{2}{*}{ 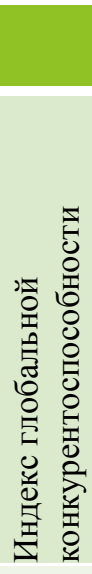 } \\
\hline & 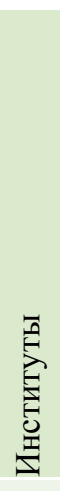 & 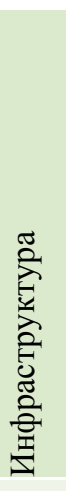 & 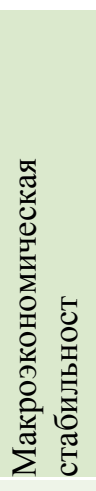 & 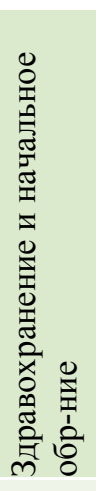 & 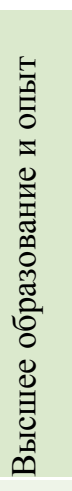 & 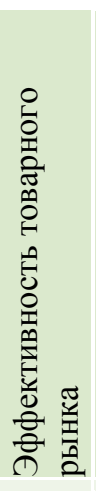 & 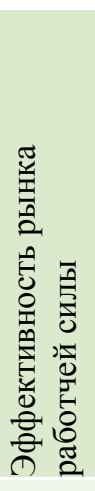 & 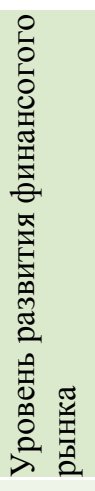 & 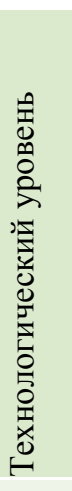 & 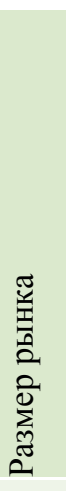 & 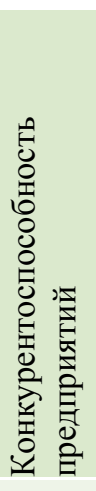 & 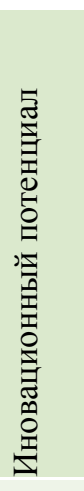 & \\
\hline Россия & $\begin{array}{l}97 \\
3.5\end{array}$ & $\begin{array}{l}39 \\
4.8\end{array}$ & $\begin{array}{c}31 \\
5.5\end{array}$ & $\begin{array}{l}56 \\
6.0\end{array}$ & $\begin{array}{l}39 \\
5.0\end{array}$ & $\begin{array}{l}99 \\
4.1\end{array}$ & $\begin{array}{l}45 \\
4.4\end{array}$ & $\begin{array}{l}110 \\
3.5\end{array}$ & $\begin{array}{l}59 \\
4.2\end{array}$ & $\begin{array}{c}7 \\
5.8\end{array}$ & $\begin{array}{c}86 \\
3.8\end{array}$ & $\begin{array}{c}65 \\
3.3\end{array}$ & $\begin{array}{c}53 \\
4.4\end{array}$ \\
\hline Казахстан & $\begin{array}{l}57 \\
4.0\end{array}$ & $\begin{array}{r}62 \\
4.2\end{array}$ & $\begin{array}{l}27 \\
5.7\end{array}$ & $\begin{array}{c}96 \\
5.4\end{array}$ & $\begin{array}{l}62 \\
4.5\end{array}$ & $\begin{array}{l}54 \\
4.5\end{array}$ & $\begin{array}{l}15 \\
4.9\end{array}$ & $\begin{array}{c}98 \\
3.7\end{array}$ & $\begin{array}{c}61 \\
4.2\end{array}$ & $\begin{array}{l}52 \\
4.3\end{array}$ & $\begin{array}{c}91 \\
3.8\end{array}$ & $\begin{array}{l}85 \\
3.1\end{array}$ & $\begin{array}{c}51 \\
4.8\end{array}$ \\
\hline Армения & $\begin{array}{l}72 \\
3.8\end{array}$ & $\begin{array}{c}78 \\
3.8\end{array}$ & $\begin{array}{l}77 \\
4.6\end{array}$ & $\begin{array}{l}99 \\
5.3\end{array}$ & $\begin{array}{r}75 \\
4.2\end{array}$ & $\begin{array}{l}64 \\
4.4\end{array}$ & $\begin{array}{l}74 \\
4.2\end{array}$ & $\begin{array}{l}97 \\
3.7\end{array}$ & $\begin{array}{c}71 \\
3.7\end{array}$ & $\begin{array}{l}118 \\
2.8\end{array}$ & $\begin{array}{c}93 \\
3.7\end{array}$ & $\begin{array}{l}104 \\
3.0\end{array}$ & $\begin{array}{l}85 \\
4.0\end{array}$ \\
\hline $\begin{array}{l}\text { Средний } \\
\text { показатель } \\
\text { ЕАЭС }\end{array}$ & $\begin{array}{r}75 \\
3.8\end{array}$ & $\begin{array}{r}60 \\
4.3\end{array}$ & $\begin{array}{l}45 \\
5.3\end{array}$ & $\begin{array}{c}84 \\
5.6\end{array}$ & $\begin{array}{l}36 \\
4.6\end{array}$ & $\begin{array}{c}72 \\
4.3\end{array}$ & $\begin{array}{l}45 \\
4.5\end{array}$ & $\begin{array}{l}102 \\
3.6\end{array}$ & $\begin{array}{c}64 \\
4.0\end{array}$ & $\begin{array}{l}59 \\
4.3\end{array}$ & $\begin{array}{l}90 \\
3.8\end{array}$ & $\begin{array}{l}85 \\
3.1\end{array}$ & $\begin{array}{c}63 \\
4.4\end{array}$ \\
\hline
\end{tabular}

Согласно исследованиям, еще одной рейтинговой кампании «Heritage Foundation» Армения и Казахстан являются “частично свободными” странами по индексу экономической свободы, Россия - “преимущественно несвободной”, а Беларусь - “полностью несвободной” (таблица 2).

Анализ основных показателей экономической свободы показывает, что в регионе ЕАЭС в основном развита фискальная, торговая свобода, свобода предпринимательства, а также положительно оценивается роль государства в экономике и свобода труда. Менее либеральны защита от коррупции, права на собственность, финансовая и инвестиционная свобода, что негативно влияет на индекс экономической свободы стран ЕАЭС.

Исследование рейтинга экономической свободы стран ЕАЭС показывает, что, по сравнению со странамичленами интеграционной группировки, у Армении самая свободная экономика. Однако, по нашему глубокому убеждению, региональная экономическая интеграция подразумевает не только либерализацию и углубление экономических отношений, но и адаптацию системы ценностей, укоренившихся в данном регионе. Достаточно привести пример стран Центральной и Восточной Европы, многие из которых, до членства в ЕС, имели статус "частично свободной” страны, а после членства, в результате становления полноценных свобод, эти страны заняли место в ряде “свободных" стран. В этом отношении интеграция со странами ЕАЭС может поставить под угрозу и без того хрупкие экономические и политические свободы РА.

Тем не менее, динамика 2012-2014гг. показывает, что страны ЕАЭС улучшили свои показатели, но это улучшение незначительно. В частности, показатели индекса свободы Армении и Казахстана в период исследования улучшились на 0,1\%, показатели России - на 1,4\%, а Беларуси - на 1,1\%.

Таким образом, анализ разных оценок конкурентоспособности стран ЕАЭС позволяет сделать вывод, что эти страны имеют сравнительные преимущества в следующих областях:

- эффективность рынка труда,

- удовлетворительный уровень образования и профессионального опыта,

- макроэкономическая стабильность,

- относительный либерализм экспорта и импорта,

- относительно сбалансированная денежно-кредитная политика, направленная на поддержание стабильности цен. 
Таблица 2. Индекс экономической свободы стран ЕАЭС в 2014г. [12] (Рейтингуются 179 стран)

\begin{tabular}{|c|c|c|c|c|c|c|c|c|c|c|c|c|}
\hline \multirow[t]{2}{*}{ Страна } & \multicolumn{2}{|c|}{$\begin{array}{l}\text { Индекс } \\
\text { экономической } \\
\text { свободы }\end{array}$} & \multicolumn{10}{|c|}{ Показатели индекса экономической свободы } \\
\hline & 思 & 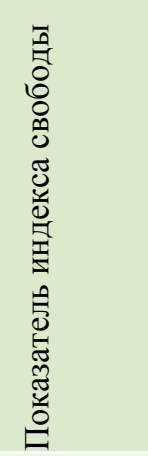 & 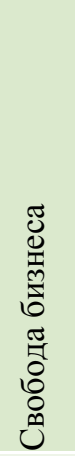 & 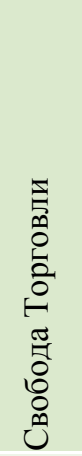 & 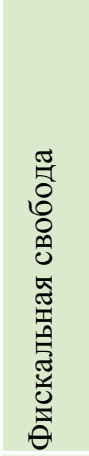 & 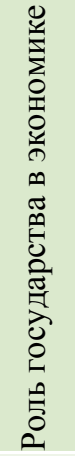 & 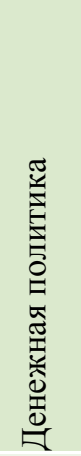 & 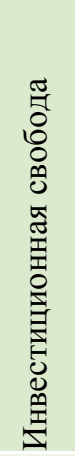 & 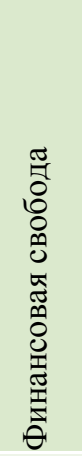 & 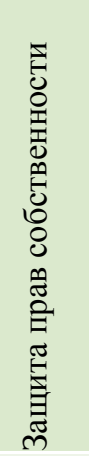 & 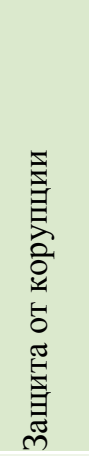 & 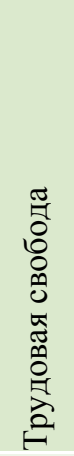 \\
\hline Армения & 41 & 68.9 & 83.1 & 85.5 & 86.5 & 81.3 & 77.0 & 70.0 & 70.0 & 30.0 & 26.7 & 78.5 \\
\hline Казахстан & 67 & 63.7 & 74.4 & 78.2 & 92.9 & 85.0 & 74.4 & 40.0 & 50.0 & 30.0 & 25.7 & 86.7 \\
\hline Россия & 140 & 51.9 & 70.0 & 74.6 & 85.6 & 61.5 & 69.4 & 25.0 & 30.0 & 25.0 & 22.1 & 55.8 \\
\hline Беларусь & 150 & 50.1 & 73.4 & 81.4 & 89.2 & 61.2 & 33.9 & 30.0 & 10.0 & 20.0 & 24.6 & 77.7 \\
\hline $\begin{array}{l}\text { Средний } \\
\text { показатель } \\
\text { ЕАЭС }\end{array}$ & 100 & 58.7 & 72.2 & 79.9 & 88.6 & 72.3 & 63.7 & 41.3 & 40.0 & 26.3 & 24.8 & 74.7 \\
\hline
\end{tabular}

В то же самое время слабые стороны конкурентоспособности стран следующие:

- низкий уровень развития финансового рынка,

- низкая эффективность государственного управления,

- неэффективность рынок товаров и услуг,

- низкая конкурентоспособность на микроуровне (предприятия),

- коррупция и высокий уровень незащищенности прав собственности,

- неэффективная инвестиционная политика.

И так, в соответствии с общей позицией рейтингов конкурентоспособности, на глобальном фоне, страны ЕАЭС можно разделить на две группы по уровню конкурентоспособности (рисунок 1). Страны ЕАЭС в среднем на 12,5\% отстают от среднего показателя мировой конкурентоспособности. Казахстан самая конкурентоспособная страна в интеграционной группировке, второе место занимает Россия, показатели конкурентоспособности, которых превышают мировой средний показатель соответственно на $29 \%$ и $26 \%$. Так значит, эти страны можно классифицировать в группе “Страны с высоким уровнем конкурентоспособности".

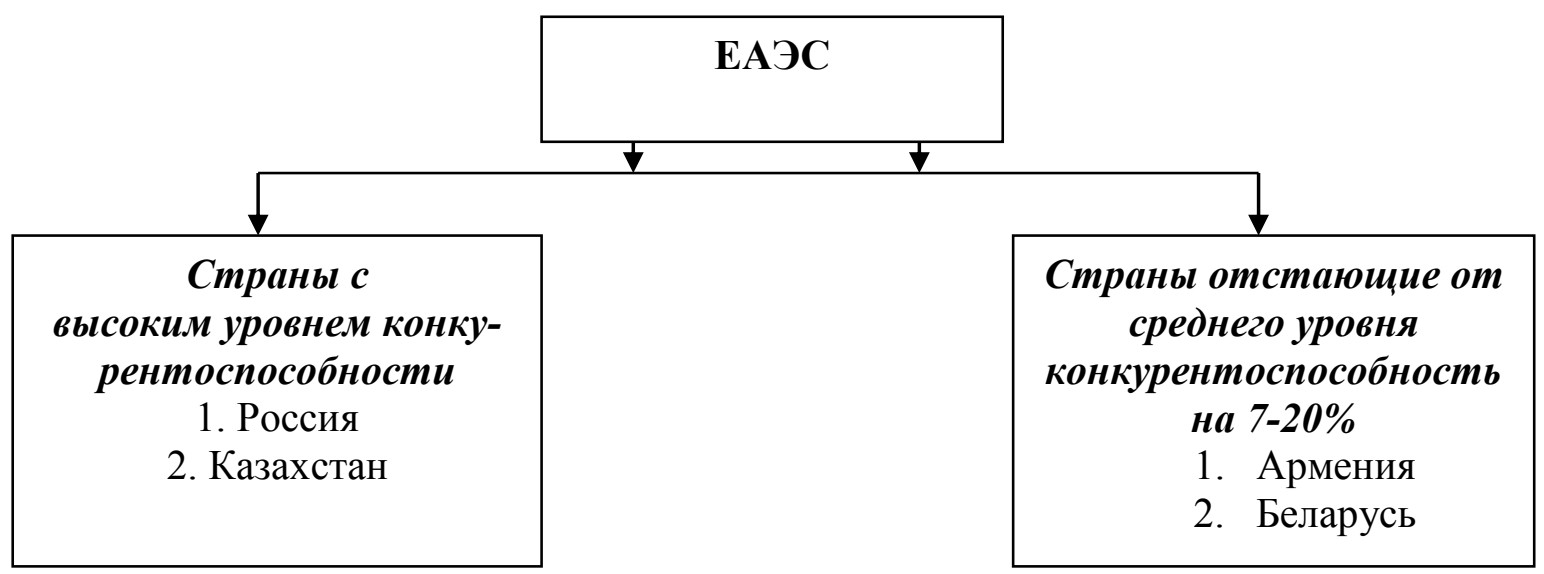

Рисунок 1 - Классификация стран ЕАЭС по конкурентоспособности 
Армения подходит к среднему мировому, отставая от этого показателя на $18 \%$, и ее можно считать членом группы “Страны среднего уровня конкурентоспособности”. Беларусь, чьи полноценные данные отсутствуют, тем не менее, можно распределить в эти группы следующим образом. Несмотря на то, что, согласно рейтингу кампании "Heritage Foundation", она имеет статус страны с несвободной экономикой, тут довольно высокий показатель доли ВВП на душу населения - 6685 долларов США и эту страну можно распределить во вторую группу, где распределена и Армения.

Конкурентоспособность Армении мы оценили и по объёму и товарной структуре торговли с странами ЕАЭС. Так 2014 году, по сравнению с 2001 годом, объем торговли Армении со странами-членами ЕАЭС увеличился в почти в 6 раз (рис. 2). Однако, кризис 2014г. сказался и на торговых отношениях, в последствии чего товарооборот между исследуемыми странами снизился на 5.4\%. Между тем передовой рост импорта над экспортом привел к постоянному отрицательному сальдо торгового баланса со странами ЕАЭС, который в исследуемом периоде увеличился в 7 раз. Несмотря на рост товарооборота между Арменией и странами Союза, большая часть торговли РА почти $96 \%$ связана с Россией.

Для оценки структурных изменений внешнеторгового оборота Армении со странами ЕАЭС, а также для выявления конкурентоспосбных отраслей важно также исследование товарной структуры импорта и экспорта (рис. 3).

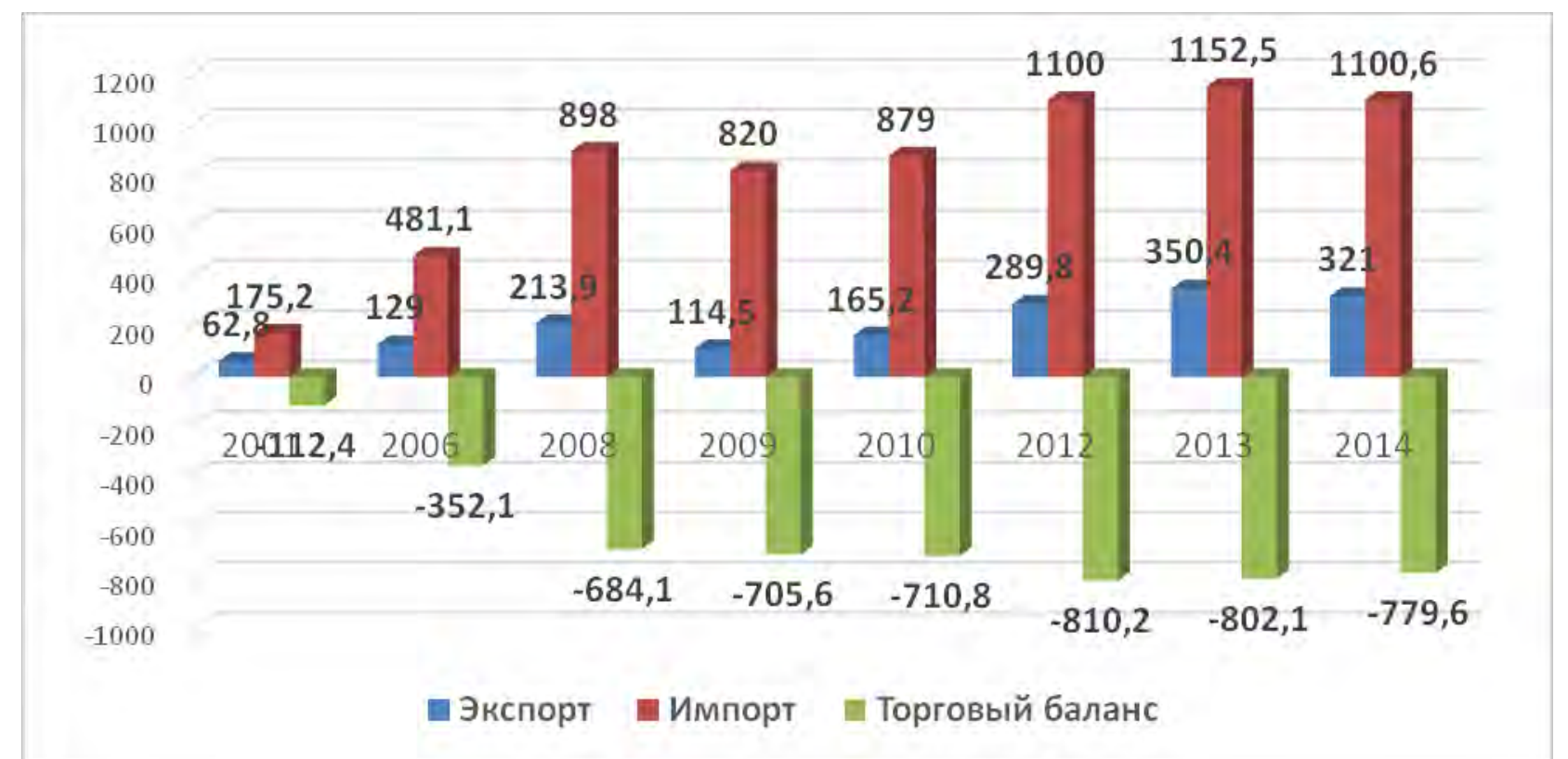

Рисунок 2 - Экспорт, импорт и торговый баланс РА и стран Таможенного союза в 2001-2014гг. (млн. доллар) [13]

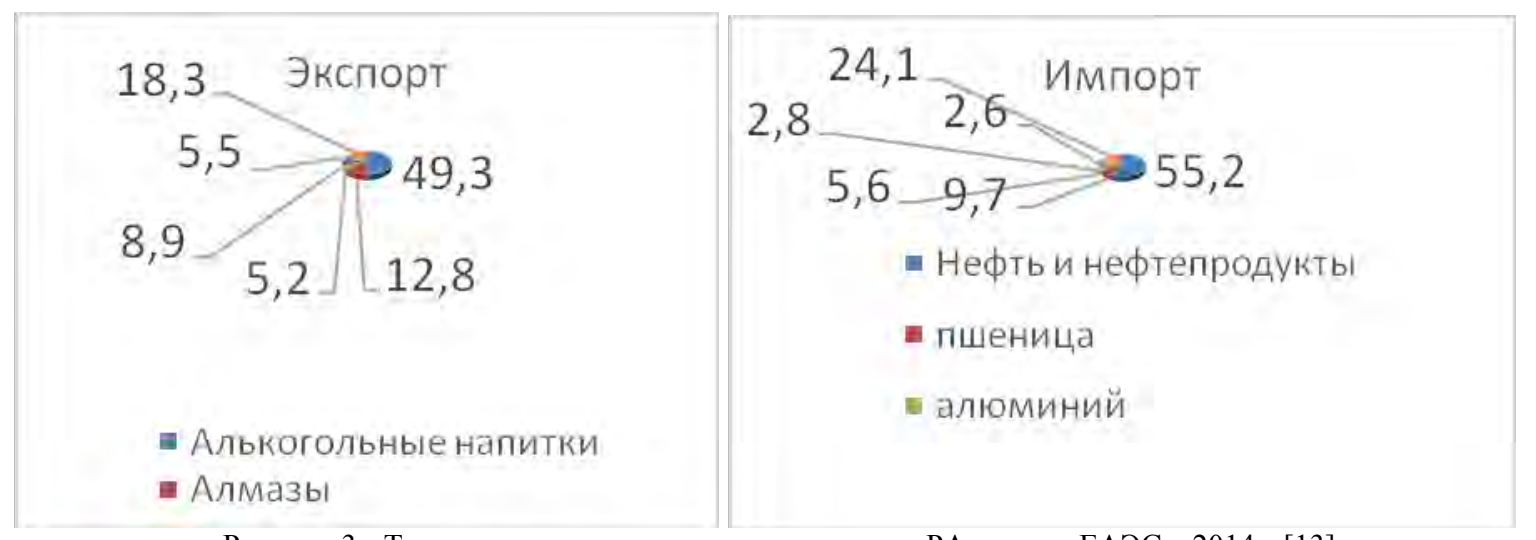

Рисунок 3 - Товарная структура импорта и экспорта РА-страны ЕАЭС в 2014г. [13]

В 2014 году 49\% экспорта из РА в страны ЕАЭС приходилось на алькогольные напитки, а 55\% импорта - на нефть и нефтепродукты. В структуре экспорта большой удельный вес имеют также алмазы, фрукты, овощи и рыба. А в структуре импорта преобладают пшеница, алюминий, животные жиры. В целом, торговля РА со странами ЕАЭС имеет высокую концентрацию. Так, на долю пяти товарных групп попадает $82 \%$ экспорта и $76 \%$ импорта.

Особой сферой сотрудничества РА и стран ЕАЭС является агропромышленный комплекс [14]. Географические и природные условия государств-членов ЕАЭС позволяют максимально использовать сравнительные преимущества сельского хозяйства, а также реализовать взаимовыгодную торговлю, отражающую интеграционные процессы аграрного рынка. Однако анализ показывает, что в этой сфере Армения имеет торговлю, основанную на относительных преимуществах только с Россией, так как такие продукты, по производству которых РА имеет высокую специализацию, в больших количествах экспортируется только в Россию. В то же время, ликвидация 
таможенных пошлин может увеличить экспорт сельскохозяйственной продукции в страны ЕАЭС, что приведет к увеличению цен на сельскохозяйственную продукцию на внутреннем рынке [15]. Например, казахстанские товары, которые без пошлин были дешевле российских, после либерализации торговли можно было легко продавать в России намного дорого, и дома они от этого тоже подорожали [16]. Этот вопрос также стал предметом широкого обсуждения в РА и требует глубокого анализа.

\section{ВЫВОДЫ}

В странах ЕАЭС основными факторами повышения конкурентоспособности можно считать повышения эффективности развития финансовых рынков, технологического уровня, внедрения инноваций и улучшения системы государственного управления. Страны ЕАЭС находятся на пути построения конкурентоспособной экономики, а в посткризисном периоде вопросы повышения конкурентоспособности становятся более важными. Осуществление эффективных структурных реформ и углубление взаимовыгодного сотрудничества в регионе может способствовать повышению конкурентоспособности стран ЕАЭС.

Итак, товарные рынки стран ЕАЭС не достаточно интегрированны, что значет, что создание экономического союза в основном выгодно для России а для других стран только в случай отдельной торголи с Россией.

Формирование развитой рыночной экономики не происходит сразу, это длительный процесс, так что формирование необходимых предпосылок для создания общего экономического пространства также зависит от четкой геополитической ориентации. В рамках ЕАЭС для расширения интеграционных процессов решающая роль принадлежит России. Она различается от стран сотрудничества темпами экономического развития, влиянием на мировом рынке, размером своей территории, природными ресурсами, поэтому будущее сотрудничества зависит именно от темпов ее экономического развития и геополитической позиции.

Россия, нынешними темпами экономического развития, не является центром экономического и технологического притяжения, не может взять на себя роль поставщика высоких и эффективных технологий, в чем нуждаются все страны-члены сотрудничества и что является основной гарантией повышения конкурентоспособности этих стран. Поэтому насколько бы не было высоко' стремление России не потерять свои бывшие экономические связи и сохранять свои лидерские позиции, тем не менее, в основе решения проблемы повышения конкурентоспособности стран, как стратегической проблемы, должно лежать выравнивание экономических условий, качество рыночных реформ и становление демократии в регионе.

\section{СПИСОК ИСПОЛЬЗОВАННЫХ ИСТОЧНИКОВ}

1. Портер, М. Конкурентное преимущество: Как достичь высокого результата и обеспечить его устойчивость / пер. с англ. Е. Калининой. - М.: «Альпина Паблишер», 2-е изд. — 2008. 720 с.

2. Smith, V. An Experimental Study of Competitive Market Behavior // Journal of Political Economy. 1962. Vol. 70. P. 34-36.

3. Kindleberger, Ch. Foreign Trade and the National Economy. Yale: Prosp. of science, 1962.

4. Tobin, J. Policies for prosperity: Essays in a Keynesian mode. New Haven: Waypoint, 1987.

5. 5.Хусаинов Б., Вызовы глобализации и усиление интеграционных процессов // «21-ый век», номер 4 (50), 2013, 83 стр.

6. Ливенцев Н. Международная экономическая интеграция // Экономисть, Москва 2006, 430 стр.

7. El-Agraa A. M. The European Union: Economics and Policies // Cambridge University Press; 9 edition, 2011, $514 \mathrm{p}$.

8. Kemp M. An Elementary Proposition Concerning the Formation of Customs Unions // Journal of International Economics 6:1, 1976 , p. 95-98.

9. The Global Competitiveness Report 2014-2015, World Economic Forum 2014.

10. The Global Competitiveness Report 2013-2014, World Economic Forum 2013.

11. MacKellar L. Economic Development Problems of Landlocked Countries //Transition Economics Series No. 14, January 2000, $21 \mathrm{p}$.

12. 2012 Index of Economic Freedom, Heritage Foundation [электронный ресурс] http://www.heritage.org/inde40.5x/ranking

13. Официальный сайт Центра Международной Торговли: //www.trademap.org/Index.aspx

14. D. Galoyan, Armenia on the Eurasec Food Market // Стратегія і механізми регулювання промислового розвитку, Зборник наукових праць, НАУ Інститут Економіки промисловості, Донецк 2013, p. 415-419.

15. Экономическое взаимодействие в агропромышленном комплексе стран СНГ // Евразийский банк развития, Отраслевой обзор Март 2010, стр. 10:

16. При вступлении в Единый таможенный союз нужно жестко отстаивать свои товары: интервью. [электронный ресурс] http://news.am/rus/news/171361.html

Статья поступила в редакцию 12 июня 2015 года. 